\title{
Las sargas y otros modos de temple: estudio comparativo experimental ${ }^{\star}$
}

\author{
Sonia Santos Gómez | Dpto. de Pintura (Pintura y Restauración), Universidad \\ Complutense de Madrid
}

URL de la contribución <www.iaph.es/revistaph/index.php/revistaph/article/view/3939>

\section{RESUMEN}

La pintura al temple sobre lienzo ha recibido diversas denominaciones en los tratados artísticos. Entre éstas, figura sencillamente el término temple, pero también el vocablo sarga, pintura aguazo y aguadas de colores. Referencias a cada uno de estos tipos de temples aparecen en tratados de diferentes épocas y la metodología y materiales empleados en ellos es similar, si bien pueden establecerse algunas desemejanzas.

El presente estudio trata de configurar un estudio comparativo experimental de tal manera puedan establecerse ciertas diferencias, sencillamente mediante su apreciación visual. Para ello, se han realizado siete probetas que corresponden a diversos modos de temple. Se han seguido las indicaciones de los tratados artísticos y antiguas ordenanzas a fin de configurarlos.

Se constata, dentro de los temples estudiados, que la pintura aguazo, debido a la metodología empleada en su ejecución, es la que más impregna el soporte, lo que se refleja de su observación por su cara posterior, y resulta, por tanto, especialmente adecuada si se persigue la estabilidad de la pintura entre las fibras textiles cuando el lienzo es utilizado para fines que impliquen su movimiento o pliegue. Esta impregnación del soporte deriva de la ausencia de preparación así como del mantenimiento del soporte húmedo mientras se pinta.

Caso aparte son las aguadas de colores, que difieren notoriamente de otros modos de temple, ya que se ejecutan sobre raso. En ellas también se aprecia una intensa impregnación del soporte.

\section{Palabras clave}

Aguadas de colores | Lienzo (Material) | Materiales | Pintura aguazo | Pintura al temple (Técnica) | Sargas | Tratados (Libros) |

*Este artículo ha sido aprobado tras ser evaluado por pares externos a ciegas. Se presentó inicialmente a la revista $\mathrm{PH}$ investigación. 

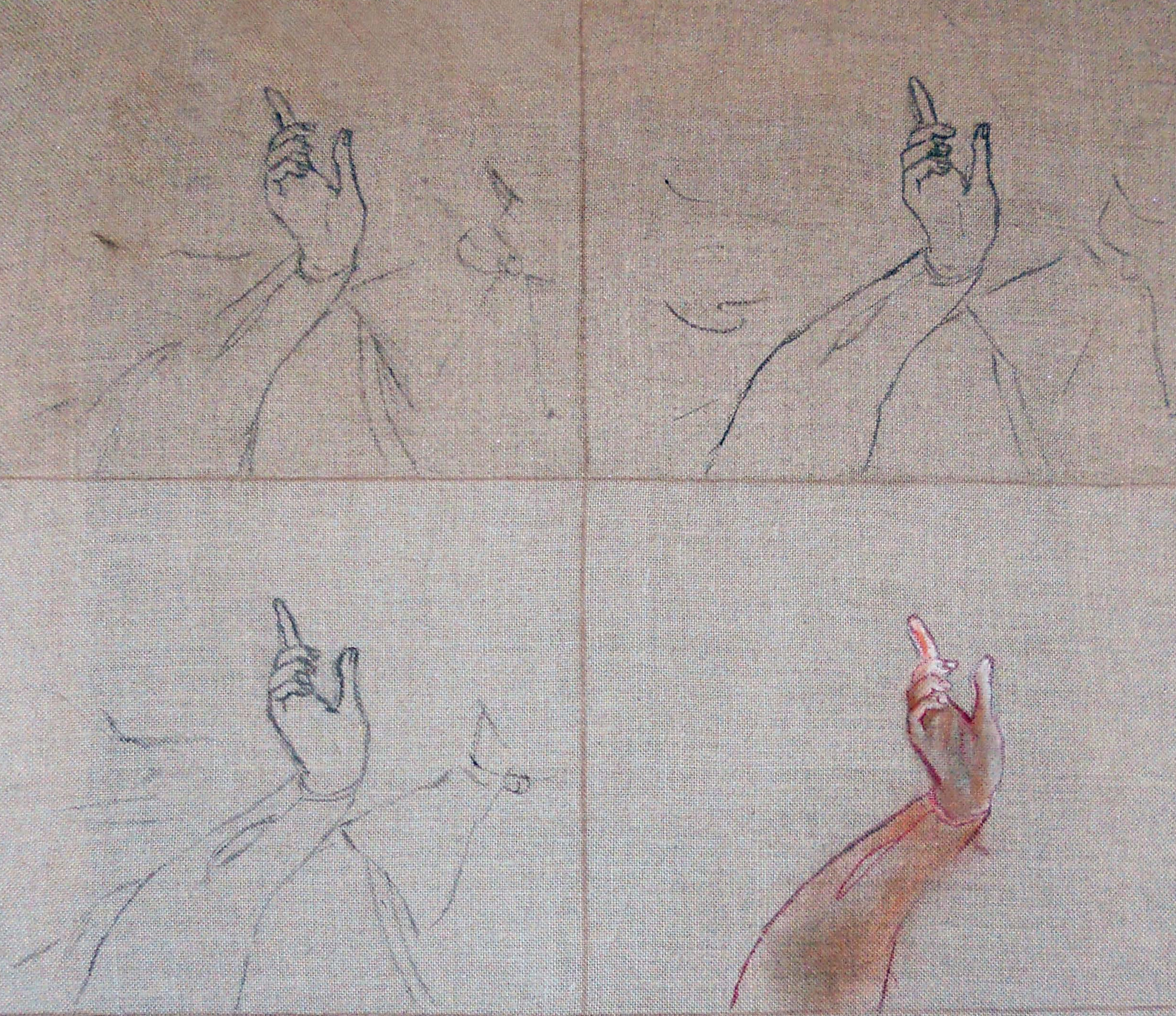

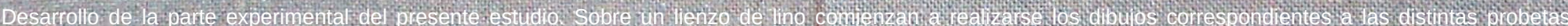

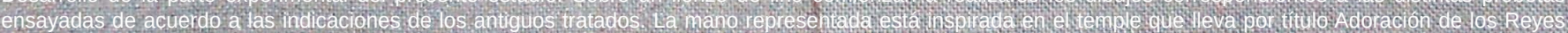

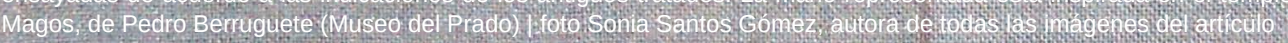




\section{INTRODUCCIÓN}

La pintura al temple se caracteriza por emplear un aglutinante que pueda ser diluido en agua, como cola, goma o huevo en mezcla con los pigmentos y ser aplicada sobre diversos soportes, fundamentalmente madera, pared, papel o lienzo. La imagen que genera el empleo de estos medios acuosos resulta más plana, menos realista que la que proporciona pintura al óleo, ya que no es tarea sencilla realizar suaves fundidos, delicadas transiciones entre zonas de luces y sombras debido a la rapidez con que seca la pintura. Por ello, las figuras representadas pueden tener una apariencia más plana o bien, cuando ya se desea una apariencia más realista, se recurre con frecuencia a los finos trazos cruzados y paralelos, de modo que éstos generan el claroscuro y los medios tonos.

Los temples sobre lienzo se utilizaban, por ejemplo, como elementos que contribuían a configurar arquitecturas efímeras destinadas a conmemoraciones de algún acontecimiento como fallecimientos o entradas triunfales, telones de teatros, cortinas de retablos, o también podían constituir doseles para camas o elementos colgantes de las paredes para contribuir a su adorno y abrigo.

A través del tiempo, tratados artísticos de todas las épocas tratan este tipo de pintura, lo que da testimonio de que no desaparece a pesar de que a partir de finales del siglo XV el óleo se manifiesta como la técnica pictórica que ocupa masivamente los retablos de pintura, así como posteriormente la pintura de género.

Dentro de la pintura al temple, la ejecutada sobre lienzo ha recibido diversas denominaciones a lo largo de la historia: pintura aguazo, aguadas de colores, sargas o, sencillamente, temples. Habida cuenta de esta variedad de términos y tipologías ¿qué distinguía a todos estos modos de temple?

Sobre todo, como se verá en los párrafos subsiguientes, serán los materiales y metodología empleados en su ejecución lo que los diferenciará, así como y la época y lugar de realización. Por otra parte cabe hacerse la pregunta sobre si, a simple vista y sin llevar a cabo ningún tipo de análisis, podría resultar posible identificarlos si llegara alguna de estas obras al laboratorio o al taller de conservación. Con esa finalidad se han realizado los ensayos aportados en la última parte de este trabajo de investigación.

\section{OBJETIVOS Y METODOLOGÍA}

Como se ha indicado, constituye un objetivo del presente estudio diferenciar los distintos tipos de temple citados en los tratados artísticos en base a los 
materiales y metodología utilizados. Por otra parte, también se pondrá de manifiesto la época en la que se ejecutaban los temples, ya que éste constituye un dato más de interés que contribuirá a su identificación. Para todo ello, se ha recurrido a la información que aportan ordenanzas de pintores $y$, fundamentalmente, a los tratados artísticos. Asimismo, algunos estudios contemporáneos han constituido referencias de base para el desarrollo de la presente investigación, ya que tratan en profundidad algunos de los temples citados, especialmente los de Rocío Bruquetas Galán (2002: 299-313); Ana Calvo, Lucila Rodríguez y Begoña Manso (2002: 449-454); y Sonia Santos Gómez y Margarita San Andrés Moya (2004: 59-74); así como algunos otros (BORREGO DÍAZ; BUCES AGUADO; CARRASCO DAMIÁN, 1999: 4-11; BUCES AGUADO, 1999: 58-70).

Por otra parte, como se ha indicado, se plantea también como objetivo fundamental conocer el aspecto que presentan los distintos modos de temple una vez han sido aplicados sobre el lienzo y si pueden ser diferenciados en base al aspecto estético de las pinceladas -con transiciones más o menos suaves-, o a través de la intensidad de la impregnación del soporte por parte de la capa pictórica.

Es especialmente interesante el estudio del aspecto que presentarían las sargas y la pintura aguazo, que pueden estar constituidos por pigmentos y aglutinantes comunes, aunque se apliquen de acuerdo a metodologías diversas. Por tanto, poder visualizar ambos temples sobre el lienzo puede resultar de especial interés para tratar de diferenciar a simple vista tipos de pinturas ejecutadas con los mismos materiales. Por otra parte, como se verá en el epígrafe subsiguiente, estos temples pueden diferir en base a otras características, como su lugar de ejecución.

\section{TIPOS DE TEMPLES SOBRE LIENZO}

Como se ha indicado algunos temples se diferencian entre sí debido a los materiales utilizados. Como ejemplo de la información aportada por los tratados artísticos, puede tenerse en cuenta la descripción que realiza Francisco Pacheco de diversos modos de temple en su Arte de la Pintura de 1649. De entre los tres modos de temple citados, él valora especialmente aquel donde las pinceladas, las formas, se funden de manera más suave, con lo que las obras pintadas adquirían un aspecto similar al óleo. En palabras del autor: "que es pintar suavemente al temple, o muy parecido al olio". En este temple se aplican como preparación dos o tres manos de cola, un dibujo a base de carbón y carmín, y como aglutinante se utiliza un huevo entero con una pequeña cantidad de leche de higuera (PACHECO, 1649: 349-350): "El lienzo bien estirado en su bastidor darle dos o tres manos de cola, no flaca ni fuerte $[\ldots]$ de suerte que los poros del lienzo se cubran i passarle la piedra 


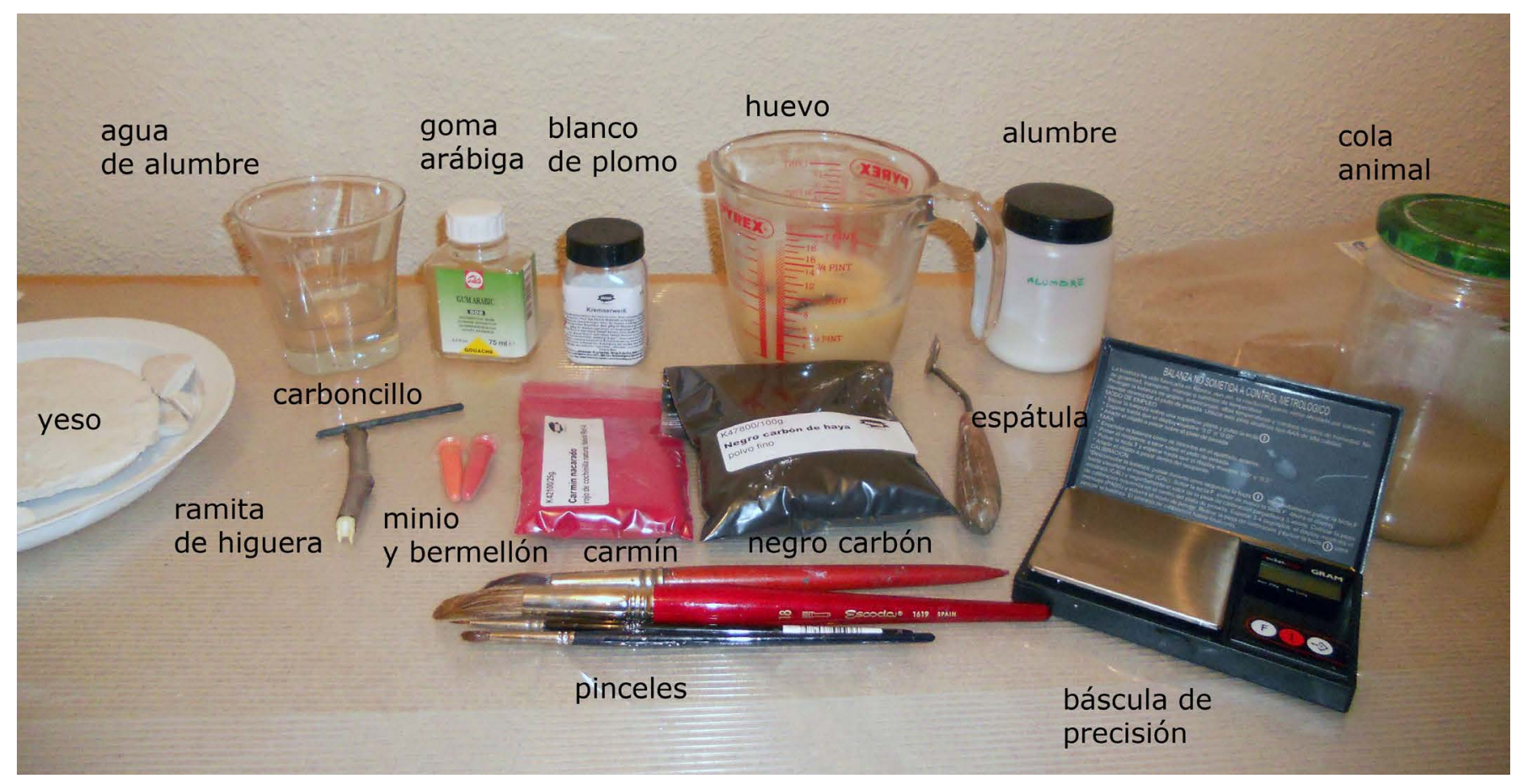

Pigmentos, aglutinantes y otros materiales utilizados en la puesta en práctica de la parte experimental del presente estudio

pomis después de seco, si está aspero, i es gruesso el lienzo. Lo segundo debuxar en el lo que se supone que está trabajado en papeles, i cartones hechos a propósito, porque todo es razón que se lleve estudiado, (que no es pintura que admite pintar uno sobre otro) assi que con carbones suaves de mimbres se debuxará toda la intención de lo que se a de pintar en el lienzo. Lo tercero con carmín, i negro juntamente, se á de perfilar la figura, o figuras i sacudido el polvo del carbón se an de comenzar a meter los colores en esta forma.

Templar un guevo entero clara, i yema con media escudilla ordinaria de agua, i echar dentro una hoja de higuera, i con un palo batirlo de suerte que levante cantidad de espuma; i con esta templa se pueden mesclar, i desatar todos los colores, que ya an de estar molidos con agua."

El empleo de la leche de higuera en el temple permitía trabajar con mayor facilidad, ya que retrasa el secado de la pintura, y su utilidad era ya conocida por Plinio El Viejo, siendo además citada por diversos autores, como Cennino Cennini en el siglo XIV (CENNINI, 1988: 124).

Otro de los temples que describe Francisco Pacheco (1649: 344-345) es aquel del que afirma que, en época de su maestro, se ejecutaba con mayor asiduidad sobre diversos soportes (lienzo o muro y parece ser que también tabla). Dentro de estas indicaciones, resultan muy interesantes las apre- 


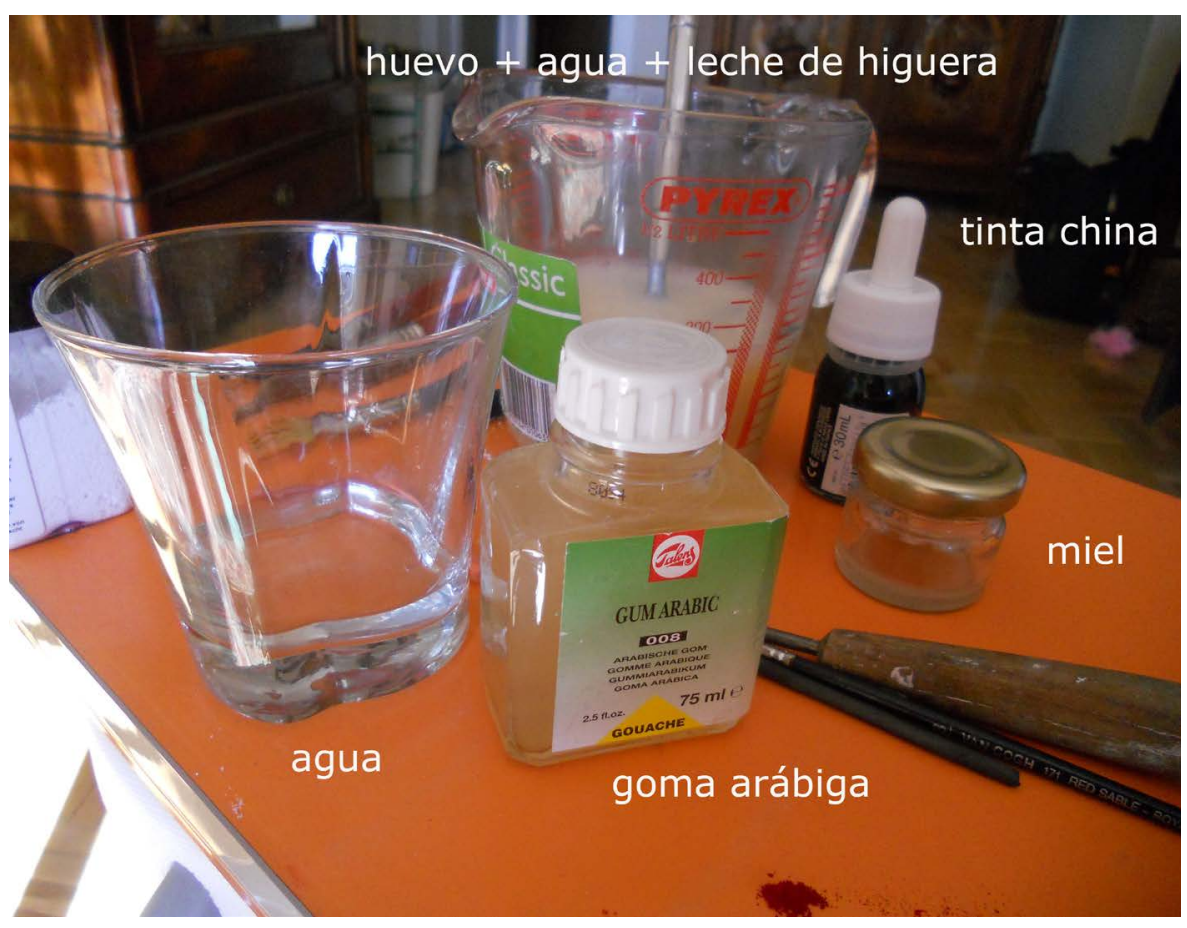

ciaciones que realiza sobre la pintura de sargas: "Esta pintura pues, se excercitaba desta manera, los colores finos que ahora se gastan, i muelen mesclados con olio de Linaza o de nuezes se molían con agua, i se echavan en escudillas, i por que no se secasen los cubrían de agua limpia; el blanco era hecho de una pella de yesso muerto, [...] este servia en las sargas de blanco, molido a l'agua i mesclado con la templa de la cola, o engrudo (como diremos) el negro era del carbón ordinario molido a l'agua, ocres claro, i oscuro, los amarillos eran de jalde, los azules en cosas de menos consideración los hazian con añil i blanco, o oscurecido con el mesmo añil, o con Orchilla echada en agua, i si los azules se gastaban en obras d consideración o eran cenizas o segundos finos, i los colorados, Bermellon, i carmín fino. Aunque en las Sargas usavan de Azarcon de la tierra, i bañaban con Brasil en lugar de carmín, i el blanco era solo yesso muerto i molido, como avemos dicho. Pero en las buenas pinturas a dos partes de yesso echavan una de albayalde; la templa del engrudo con que se desatavan estos colores era desta manera lo mas ordinario: la cola [...] con esta templa daban primero el lienzo, o pared, i mesclavan los colores, i para averlos de gastar siempre tenia el fuego a la mano $[\ldots]^{\prime \prime}$.

De los párrafos anteriores parece deducirse que, tanto este temple general que describe Pacheco, como las sargas se pintaban con cola como aglutinante. La capa de preparación era la misma cola. Pueden destacarse también algunos pigmentos o cargas que el autor vincula directamente con
Aglutinantes y otros materiales utilizados en la puesta en práctica de la parte experimental del presente estudio

El jalde es un pigmento amarillo, sulfuro de arsénico $\left(\mathrm{As}_{2} \mathrm{~S}_{3}\right)$; el añil, de color azul, tiene origen vegetal y el colorante se obtenía a partir de la maceración en agua de hojas y tallos de ciertas plantas del género Indigofera o del glasto (Isatis tinctoria); la orchilla se elaboraba a partir de un liquen (Roccella canairensis) del que se extraía un colorante; las cenizas o segundos finos son azurita $\left(\left(2 \mathrm{CuCO}_{3} \cdot \mathrm{Cu}(\mathrm{OH})_{2}\right)\right.$; bermellón, sulfuro de mercurio artificial $(\mathrm{HgS})$; el azarcón es un pigmento rojo, tetróxido de plomo $\left(\mathrm{Pb}_{3} \mathrm{O}_{4}\right)$; Brasil hace referencia a una laca rojiza elaborada a partir del colorante del mismo nombre; y el yeso muerto y molido es sulfato de calcio dihidrato $\mathrm{CaSO}_{4} \cdot 2 \mathrm{H}_{2} \mathrm{O}$. 
El azul fino muy probablemente sea azurita $\left(2 \mathrm{CuCO}_{3} \cdot \mathrm{Cu}(\mathrm{OH})_{2}\right)$; prieto es un pigmento negro; "amir" se refiere al añil; y "rosete fecho de brasil" hace referencia a la laca roja ya citada. la pintura de sargas: yeso, azarcón y Brasil. El resto de los mencionados (negro de carbón, jalde, añil, orchilla, cenizas, albayalde) seguramente eran empleados en la pintura de sargas, aunque la redacción del texto impide realizar afirmaciones taxativas a este respecto.

Las Ordenanzas de Córdoba de 1493 (RAMíREZ DE ARELLANO, 1913: 39-40) definen de manera más precisa la pintura de sargas y constituyen un documento esencial para su comprensión, en tanto a materiales y metodología empleados. Recomiendan como aglutinante cola, como se ha indicado y, para "cosas sotiles", huevo. Como preparación se aplicaba cola mezclada con un poco de miel y, sobre la misma, yeso molido con agua en ciertas zonas como las encarnaciones (SANTOS GÓMEZ; SAN ANDRÉS MOYA, 2004: 66-68).

"Primeramente ordenamos e mandamos que doquiera que obieren figuras de imágenes que después de debuxadas que sean perfiladas de negro los cuerpos e matizadas e después muy bien emprimadas de su cola de engrudo de pergamino o de vacas. E con esta tal engrudo abiendo el conocimiento verdadero de su templa que se eche alguna miel asy porque hace blandos los asientos de las colores e aun porque non quiebran doblando el paño.

Otro si ordenamos que sobre esta tal emprimadura aya otra de yeso molido con agua e templado con este tal engrudo non espeso salvo en buena manera e esto se entienda en los rostros... e manos de las imagines porque ha de ir cubierto de color e en todos los cuerpos destas imagines e en los brocados e otras obras de fuera destas imagines han de ser templadas las colores e matices de toda la obra con este dicho engrudo guardando todavía que las dichas colores que se asienten muy delicadamente en manera que non fagan mucho cuerpo porque sean firmes. Entre estas templas que aya otra de huevos que llaman templa con que se perfilan las cosas sotiles.

Otro si ordenamos e mandamos que las colores conque se ayan de pyntar las dichas sargas después de lo suso dicho sean con buen albayalde e buen bermellón e buen jalde e buen amir e ocre e prieto e buen rosete fecho de brasil e azul fino si las partes lo pidieren a que estas colores sean bien molidas porque son mas firmes e dan mas vista"2. (RAMíREZ DE ARELLANO, 1913: 40).

Insisten las ordenanzas en que "ninguno non sea osado de pintar ninguna imagen salvo siendo encolada" (RAMÍREZ DE ARELLANO, 1913: 40) y, por otra parte, la indicación de que "las colores se asienten muy delicadamente de manera que non fagan mucho cuerpo porque sean firmes" se refiere a que la pintura no debe tener mucho grosor o podría sufrir pérdidas si el lienzo experimentara algún tipo de movimiento, durante su utilización, ya 
fuera como cielos o doseles de camas, sustitutos de tapices o alguna función religiosa ${ }^{3}$. Debe recordarse que capa pictórica y preparación de las sargas son magras y, por tanto, rígidas al secar y han sido aplicadas sobre un soporte móvil como el lienzo.

Las sargas tuvieron su época de especial difusión en el siglo XVI. Las Ordenanzas de Madrid de 1543, a diferencia de las anteriores de Córdoba de 1493, prohibían, sin embargo, la aplicación de preparaciones, indicando a los pintores que "no aparejen los paños" (AGULLÓ Y COBOS, 1978: 193194). Esta afirmación excluye una aplicación de yeso y cola, aunque no es seguro de que excluya también una capa de cola. Sin preparación o mediante la aplicación de una fina capa, se mantiene en mayor medida la flexibilidad del soporte.

La diferencia entre sargas y el primer temple referido estriba, más que en la preparación, donde los textos que hacen referencia a las sargas no son unánimes, en el aglutinante empleado, ya que aunque también puede emplearse huevo en las sargas, en principio sólo se utilizaría en sutilezas, no de manera general y en realidad se utilizaría fundamentalmente cola animal en éstas. Respecto al dibujo, mientras para la pintura de sargas se recomendaba carmín, en el temple de Pacheco se hace referencia, además de al carmín, al negro.

Otro tipo de pintura al temple sobre lienzo referido por Francisco Pacheco, así como por otros autores, son las denominadas aguadas de colores, que consistían en pintar al temple sobre diversos soportes, como papel, tafetán o lienzo, preparándolos con alumbre y templando los pigmentos con goma, como si se tratara de acuarela (PACHECO, 1649: 351). Este tipo de temple, por tanto, difiere notoriamente de las otras tipologías por los aglutinantes y la preparación utilizados, y porque quizás estaría más bien destinado a lienzos más finos elaborados con fibras nobles, posiblemente seda, acaso para que fueran vistos por ambas caras. Los otros modos de temple referidos es más probable fueran ejecutados sobre lino en la mayoría de los casos, aunque los tratadistas no se refieren a este aspecto. El alumbre aplicado sobre el soporte de las aguadas podría fijar los colorantes aplicados sobre este tipo de obras ya que algunas de las materias que aportan color carecen de cuerpo y son colorantes. Pacheco incluye entre ellas azafrán, añil, carmín, y granillo. Por otra parte algunos colorantes, entre los que se encuentran los utilizados para elaborar las lacas rojas, como el carmín, también eran preparados habitualmente con alumbre para su utilización como material pictórico (PALOMINO, 1988: tomo II, 523-525).

Estas aguadas de colores son referidas por otros tratadistas del siglo XVII e incluso aparecen en ciertos textos del siglo $\mathrm{XX}^{4}$, pero la siguiente referencia corresponde a la ya citada de Francisco Pacheco:
Sobre la temática, época y función de las sargas, la autora del presente trabajo ha escrito un artículo que actualmente está siendo sometido a revisión: "La Pintura de Sargas ( $2^{\mathrm{a}}$ parte): Nuevos datos relativos a la utilidad de estas obras y la temática representada en ellas" (Sonia Santos Gómez, 2017).

4

En el Tractado del arte de la pintura, anónimo del siblo XVII, (SANZ, 1978: 270) se describen las "aguadas de colores" como un tipo de pintura ejecutada sobre papel, tafetán o lienzo u otra tela blanca, preparando el soporte con agua de alumbre y aglutinándose los pigmentos con goma. Los pigmentos a emplear son "carmín de Indias, arrebol de mujeres, añil, azul de trapillo, verde vejiga o de granillo, verde cardenillo con ruda, urchilla, azafrán con zumo de limón o vino". El carmín de Indias seguramente es el de cochinilla. Arrebol es un pigmento rojo, empleado como maquillaje en los rostros de las mujeres (RELLO, 2008). El azul de trapillo es un pigmento de difícil identificación. Quizás, como indica Corinna Gramatke, podría tratarse de un colorante (¿añil?) o de un pigmento obtenido a partir de las costras que se forman sobre las planchas de cobre (obtención de manera similar al cardenillo) (GRAMATKE, 2005). El verde granillo quizás sea crisocola o malaquita tal y como indica el Pigment Compendium (EASTAUG, 2004: 384). El verde vejiga es un pigmento laca obtenido a partir de un colorante vegetal (bayas de espino cerval y un álcali y alumbre). Era guardado en vejigas de cerdo. La ruda es una planta que tenía usos en múltiples ámbitos y cuyo jugo intensificaba el color del cardenillo. A la urchilla u orchilla ya se ha hecho referencia con anterioridad. Vicente Carducho en su Diálogos de la pintura de 1633 describe las "aguadas de colores" de similar forma al autor anterior. Indica que se realizan sobre papel, tafetán o lienzo "ó otra cualquiera tela blanca" (CARDUCHO, 1981: 381). También Ronchetti en su Manual para los aficionados a la pintura (1912: 358) se refiere a este tipo de pintura. 
5

La ancorca es, de acuerdo a Palomino de Castro y Velasco: "Artificial de yeso mate, y tinta de gualda" (1988: Tomo II, 556).

6

El verde montaña es malaquita $\left(\mathrm{Cu}_{2} \mathrm{CO}_{3}(\mathrm{OH})_{2}\right)$.
"Tambien se puede ofrecer pintar algo sobre raso, o tafetán, por mas brevedad a temple, i lo primero a de ser blanco, i puesto en su bastidor, echar a cozer en agua dulce un poco de alumbre, i estando deshecho, i frio, con un pañito limpio bañar el raso, o tafetán, i después de enjuto perfilar lo debuxado, o estarcido con tinta, dándole sus aguadas de colores templadas con goma flaca, pero an de ser las que no tienen cuerpo, como azafran por amarillos con unas gotas de aguardiente; por azul añir u Orchilla, por colorados carmín, por verdes granillo, sombra de Italia, i encorca, i estas aguadas sirven por ambas partes i los amarillos parecen oro"s.

Otro de los temples descritos por Francisco Pacheco es la pintura aguazo, que se diferencia de las sargas fundamentalmente en la metodología empleada en su ejecución, como ya se ha anticipado. Es interesante poner de manifiesto que este autor considera que, en su época, la pintura aguazo no era practicada en España, aunque sí lo fuera en Italia y Flandes. Por otra parte, menciona la necesidad de realizar pruebas de color, y esperar a que sequen, debido a que el aguazo modifica su color después de este secado. El artífice necesitaba de la labor de un ayudante a fin de que fuera humedeciendo el lienzo por detrás, mientras él aplicaba por la cara anterior la pintura al temple a la cola. Además de los pigmentos incluidos para el primer temple citado, incluye el verde montaña, tierra verde y el verde granillo (PACHECO, 1649: 347-348)

"La pintura aguazo que oi usan los Flamencos e Italianos, i Cespedes dize que aprendio en Italia, quien tiene della alguna noticia dize ser assi.

Que teniendo la templa del engrudo que diximios, o el Retazo de guantes cozido como para yesso mate, i los colores molidos a l'agua, aviendo hecho la experiencia, probando el color templado en el lienzo, i aguardando a que se enjugue; para que no salgan los colores muy escuros, o mui claros, sino como quiere el Artifice [...] Queriendo oscurecer con las primeras i segundas tintas, i realzar su pintura, se vale el Maestro de ir vmedeciendo el lienzo por detrás en lo que va haciendo, mandando que una persona le vaya bañando con agua la parte que quiere acabar, i assi va uniendo entre si fácil, i dulcemente cualquier genero de pintura: sean cielos, países, ropas o carnes; i particularmente es avantajado este modo cuando lo que se pinta es de blanco, i negro, o de color de Bronze. I verdaderamente dixo bien un Italiano; que la pintura Aguazo era de Casta de Patos porque toda es agua i mas agua. [...] I por esta causa los esperimentados tienen por mas conveniente, en esta pintura guazo la cola o engrudo de guantes, o el de tajadas aguado, que no el guevo, porque demás de ser costoso, con l'agua se enflaquece: i si es mucha la pintura fuera menos costosa la templa del engrudo.

I aunque yo no e experimentado este modo me parece bien i lo venero, por ser tan usado de valientes hombres en Italia, i en Flandes, donde tan dul- 
cemente, con tanta destreza i hermosura de colores se exercita [...] De los colores avemos dicho, añadiendo aora el verde montaña, verde terra, i verde granillo, que todos tres se usan todo genero de temple".

Esta metodología de trabajo daría lugar a la profunda penetración de la capa pictórica en el soporte que, por otra parte, carecía de preparación, con lo que mantenía su flexibilidad a fin de que la obra pudiera cumplir su función.

Giorgio Vasari (1986) da testimonio de la práctica de la pintura a guazzo en la Italia del siglo XVI al referirse a ella en Le vite de' piú eccellenti architetti, pittori, et scultori italiani... (ed. prínc. Florencia 1550). Este autor indica que se empleaba para decorar teatros, fiestas o arcos de triunfo. El aglutinante referido es cola animal y, a diferencia de la pintura de sargas y los otros tipos de temple, como Pacheco, indica que la tela ha de permanecer húmeda mientras se pinta.

La pintura aguazo llega al siglo XVIII, siendo descrita por Antonio Palomino de Castro y Velasco en el Museo pictórico y escala óptica (1988: tomo I, 142143; tomo II, 556) de manera muy similar a la de Pacheco:

"El aguazo se hace sobre lienzo blanco, y delgado, humedeciéndolo por el reverso con agua natural, y sin más blanco, que el de la superficie. Esto se dibuja primero sobre el mismo lienzo en seco, con un carbón muy suave, y dócil, puesto en una caña, a proporción de la superficie; y lo que se yerra, se sacude con unas plumas; y asegurados, que sean, los perfiles, se van pasando en seco con una aguadita de carmín muy delicada, tanto, cuanto se vea, con agua cola, o goma muy flaca; y después se va humedeciendo con una brocha grande por el reverso aquella porción que se ha de pintar (y la humedad no sea demasiada) y usando de las aguadas, según conviene al valor de cada cosa, se va concluyendo: con advertencia, que conviene acabar primero, lo que se supone estar delante, y luego como se sigue; porque no se puede borrar lo hecho"

Palomino señala que estas pinturas eran empleadas a modo de cortinas en los teatros y como sustitutos de los tapices. La ausencia de preparación y la penetración en el soporte de la capa pictórica permite el movimiento de las obras, de acuerdo a su función, reduciéndose el riesgo de la aparición de lagunas. A ello también contribuye otra indicación del texto, que hace referencia a la indicación del empleo como blanco del tono del lienzo ("blanco y delgado").

Por otra parte, el término aguazzo ha designado, durante siglos, genéricamente, la pintura al temple sobre diversos soportes (SANTOS GÓMEZ; SAN ANDRÉS MOYA, 2004: 71-73). Paolo Pino en Dialogo di pitvra (1548) alude a las dos técnicas para pintar en seco sobre muro indicando que se 


\begin{tabular}{|c|c|c|c|}
\hline \multicolumn{4}{|c|}{ TABLA 1. MODOS DE TEMPLE REFERIDOS } \\
\hline TIPOS DE TEMPLE & ÉPOCA & MATERIALES & METODOLOGÍA \\
\hline $\begin{array}{l}\text { Temple parecido al } \\
\text { óleo, de F. Pacheco }\end{array}$ & F. Pacheco 1649 & $\begin{array}{l}\text { Preparación: dos o tres manos de cola } \\
\text { Dibujo: carbones y repaso con carmín y negro } \\
\text { Aglutinante: huevo y una ramita de higuera } \\
\text { Pigmentos: Todos los colores. Los pigmentos se muelen } \\
\text { con agua. }\end{array}$ & Pincel \\
\hline \multirow{3}{*}{ Sargas } & $\begin{array}{l}\text { Ordenanzas de } \\
\text { Córdoba de } 1493\end{array}$ & $\begin{array}{l}\text { Primero el dibujo. Después perfilado de negro. } \\
\text { Preparación: cola+miel. Capa de yeso (seguramente con } \\
\text { cola) } \\
\text { Aglutinante: cola. Puede utilizarse el huevo. } \\
\text { Pigmentos: Albayalde, bermellón, jalde, amir, ocre, } \\
\text { prieto, rosete de Brasil, azul fino }\end{array}$ & \multirow{3}{*}{ Pincel } \\
\hline & $\begin{array}{l}\text { Ordenanzas de Madrid } \\
\text { de } 1543\end{array}$ & Preparación: Sin preparación. & \\
\hline & $\begin{array}{l}\text { F. Pacheco } 1649 \\
\text { (referencias } \\
\text { específicas a las } \\
\text { sargas) }\end{array}$ & $\begin{array}{l}\text { Aglutinante: cola } \\
\text { Preparación: seguramente cola } \\
\text { Pigmentos específicos de las sargas: yeso como } \\
\text { blanco, azarcón, Brasil (posiblemente también los otros } \\
\text { pigmentos citados en este antiguo temple: negro de } \\
\text { carbón, jalde, añil, orchilla, cenizas, albayalde) } \\
\text { Se molían con agua }\end{array}$ & \\
\hline \multirow{2}{*}{ Aguadas de colores } & \multirow{2}{*}{$\begin{array}{l}\text { Citadas por F. } \\
\text { Pacheco y otros } \\
\text { autores en el s. XVII }\end{array}$} & $\begin{array}{l}\text { Preparación: agua de alumbre } \\
\text { Dibujo: Se perfila con tinta }\end{array}$ & \multirow{2}{*}{ Pincel } \\
\hline & & Aglutinante: goma diluida ("flaca") & \\
\hline \multirow[t]{2}{*}{ Pintura à guazzo } & F. Pacheco & $\begin{array}{l}\text { Preparación: ausencia de preparación (agua) } \\
\text { Aglutinante: Cola. } \\
\text { Pigmentos: verde montaña, verde terra, granillo, además } \\
\text { de los incluidos en el temple que relaciona con la pintura } \\
\text { de sargas (Yeso muerto, negro de carbón, jalde, añil, } \\
\text { orchilla, cenizas, bermellón, carmín, azarcón, Brasil, } \\
\text { albayalde) } \\
\text { Pigmentos molidos con agua }\end{array}$ & \multirow[t]{2}{*}{$\begin{array}{l}\text { Brocha grande } \\
\text { con agua por el } \\
\text { reverso y se pinta } \\
\text { con aguacola y } \\
\text { pigmentos por la } \\
\text { cara anterior }\end{array}$} \\
\hline & $\begin{array}{l}\text { A. Palomino } \\
1715-1724\end{array}$ & $\begin{array}{l}\text { Dibujo: carbón y se aseguran perfiles con carmín + } \\
\text { aguacola o goma }\end{array}$ & \\
\hline
\end{tabular}

trata de pintura à oglio (al óleo) y à guazzo (al temple) (PINO, 1548: 20r). También, Roger de Piles en Les premiers éléments de la peinture pratique (ed. prínc. 1684) hace referencia a la pintura al temple sobre telas, tabla, piel y papel indicando que los italianos la denominaban "guazzo" (1973: 85) y para Francisco Martínez en su Introducción al conocimiento de las bellas artes. Diccionario de Pintura, escultura, arquitectura y grabado (1788) la pintura "que llaman aguazo y aguada los italianos" era pintura al temple, en la que el aglutinante era cola o goma y los soportes yeso, madera, pergamino y papel (MARTÍNEZ, 1989: 329). 
Muchas veces al temple se ejecutaban pinturas en grisalla o también de color pardo. Por ejemplo, respecto a la pintura aguazzo, Vasari refiere la ejecución con esta técnica de claroscuros, mediante el empleo de pigmentos blancos, negros y rojizos (VASARI, 1986: 71-72). Por su parte Francisco Pacheco indica que el aguazo resultaba especialmente útil en pintura "de blanco y negro, o de color de bronce" (PACHECO, 1649: 348). Pero también, dentro de los tipos de sargas, algunos documentos, como las Ordenanzas de Sevilla de 1527, hacen referencia a las sargas de diversos colores "sargas blancas, de colores y pardillas" (ORDENANZAS, 1527: CLXIII-CLXIIII).

La tabla de la página anterior constituye un resumen de los diversos modos de temple referidos.

Por otra parte, son numerosos los autores que hacen referencia a la pintura al temple sobre lienzo y otros soportes en general, a lo largo de los siglos y sin denominarlos sarga, aguazo, o aguadas de colores. Entre estos autores están Felipe Nunes, que indica que la pintura al temple sobre lienzo empleaba como aglutinante cola. Como capa de preparación se aplicaba una mano de cola a la que podía añadirse blanco de plomo. Este último punto diferencia este temple de los otros referidos (SANTOS GÓMEZ; SAN ANDRÉS MOYA, 2004: 74; NUNES, 1615: 59v-60r).

El Tractado del Arte de la Pintura (s. XVII) describe la pintura al temple como realizada en lienzo, pared o tabla, con preparación de cola y yeso, empleando pigmentos aglutinados con cola, huevo, leche o goma. Los pigmentos recomendados son todos en general, incluyendo el verde granillo o vejiga, urchilla, azafrán, carmín de indias, negro de rasuras de vino, azarcón y albayalde (SANZ, 1978: 269-270) y Vicente Carducho en su Diálogos de la pintura, de 1633, describe el temple de similar forma que el autor anterior (1981: 380,383) indicando que se utiliza cola, huevo, leche o goma y se hace sobre lienzo, pared o tabla. También Antonio Palomino define la pintura al temple como ejecutada sobre pared, lienzo, tabla, pergamino, papel, seda y cabritilla, y los pigmentos se aglutinan con "cola, goma o cosa semejante" (1988: tomo I: 138-143; tomo II: 218-231). La preparación referida esta vez está constituida por yeso y ceniza. J. Soler Oliveres describe la pintura al temple de forma muy similar a Palomino (SOLER OLIVERES, 1998: 106-109).

Para el profesional conservador-restaurador o el investigador que recibe una pintura al temple sobre lienzo en su taller o laboratorio no es fácil distinguir visualmente si se trata de un tipo de temple $u$ otro, de los mencionados, ya que los materiales empleados pueden llegar a ser muy similares. Por ejemplo, como se recordará, en las sargas se utiliza cola como aglutinante y ciertos textos recomiendan la ausencia de preparación en las mismas (las Ordenanzas de Madrid, refiriéndose a la pintura de sargas, prohibían que 
se prepararan los lienzos). En estos casos, quizás pudiera diferenciarse una sarga de un aguazo en base a la penetración de la pintura en el soporte. $\mathrm{Si}$, cuando se pinta aguazo, se mantiene húmedo el soporte en la zona que se está aplicando la pintura, sin duda esta pintura que se aplica por el anverso mojará o impregnará en mayor medida el soporte, ya que se difundirá a través del agua que impregna el lienzo.

Por otra parte, por supuesto, a la hora de identificar los temples, sería fundamental estudiar el ámbito geográfico en el que se han ejecutado, así como la época. Como se ha indicado, la pintura de sargas tiene su época de producción masiva en el siglo XVI mientras que, en el siglo XVII, en la época de Pacheco, la técnica del aguazo no se ha difundido en nuestro país.

A fin de comprobar el aspecto que presentarían los tipos de temple citados, se han realizado pequeñas probetas que muestran el aspecto de estas obras y las impregnaciones que se producen en el soporte. Los resultados obtenidos serán presentados en el siguiente epígrafe.

\section{ESTUDIO VISUAL COMPARATIVO DE DIVERSOS MODOS DE TEMPLE}

Para llevar a cabo el estudio visual comparativo de los temples se han realizado 7 pequeñas probetas: una sarga, según los materiales y metodología descritos en las Ordenanzas de Córdoba de 1493, otra ejecutada según Francisco Pacheco, otra sarga similar a la anterior pero sin preparación, de acuerdo a la indicación de las Ordenanzas de Madrid de 1543, el temple descrito por Francisco Pacheco como suave y similar al óleo y dos aguazos, pintados teniendo en cuenta las indicaciones de este autor y de Antonio Palomino. Todos ellos han sido ejecutados sobre soporte de lino, aunque los tratados artísticos que hacen referencia a ellos no se pronuncian a este respecto. De los dos aguazos citados, uno ha sido ejecutado sobre lino, con el color que este tejido suele presentar, pardo, y otro más blanco, siguiendo la indicación de Antonio Palomino. Además, se han pintado sobre raso blanco de seda unas aguadas de colores.

La tabla siguiente aporta la metodología y materiales empleados, pero, a continuación, se realizan algunas puntualizaciones:

Se ha utilizado, tanto como aglutinante, como capa de preparación, cola animal en grumos (de la marca Manuel Riesgo), hidratada en proporción 1:10. De esta cola hidratada y fundida se han aplicado $10 \mathrm{ml}$ como preparación en cada zona correspondiente a cada una de las probetas (en concreto en el temple 2, temple 5 y en el 1 , en este caso mezclada con $1 \mathrm{~g}$ de miel). Esta cola fundida se ha utilizado también como aglutinante en todos los temples menos en los 5 y 7. 
Los pigmentos empleados han sido blanco de plomo, azarcón, bermellón y carmín de la casa comercial Kremer.

El alumbre utilizado es de la casa comercial Merk y la tinta china de la marca Nan-King. La goma arábiga utilizada es de Talens (diluída en agua en proporción 1:2).

El yeso utilizado como preparación en el temple 1 o como pigmento en los temples 2, 3 y 4 es el aludido por F. Pacheco "no de muchos días como el mate, sino muerto como el de modelos molido al agua" (Pacheco, 1649:344). Se ha utilizado en su preparación una escayola E-35, que se ha molido con agua.

La siguiente tabla muestra los materiales empleados en la realización de cada una de estas probetas, así como la metodología seguida en su elaboración, de acuerdo a las indicaciones de los antiguos tratados y ordenanzas:

\section{TABLA 2. MATERIALES Y METODOLOGÍAS SEGUIDAS EN LA ELABORACIÓN DE LOS TEMPLES}

\begin{tabular}{|c|c|c|}
\hline TEMPLE & MATERIALES & METODOLOGÍA APLICADA \\
\hline $\begin{array}{l}\text { Temple } 1 \\
\text { Sarga. Ordenanzas de } \\
\text { Córdoba de } 1493\end{array}$ & $\begin{array}{l}\text { Carbón } \\
\text { Negro carbón } \\
\text { Cola } \\
\text { Miel } \\
\text { Yeso } \\
\text { Albayalde } \\
\text { Bermellón }\end{array}$ & $\begin{array}{l}\text { Realización del dibujo: se utiliza un palito de carbón aunque el texto no } \\
\text { lo indica). Después, de acuerdo al texto, se perfila el dibujo con negro } \\
\text { (se mezcla para ello negro carbón con cola) y después se aplica una } \\
\text { capa de cola a la que se añade una pequeña cantidad de miel (10 g de } \\
\text { cola y } 1 \mathrm{~g} \text { de miel). En las figuras se aplica una ligera preparación de } \\
\text { yeso molido con agua y templado con cola. Después se pinta utilizando } \\
\text { cola como aglutinante. Como pigmentos podrían utilizarse, de acuerdo a } \\
\text { las ordenanzas, albayalde, bermellón, jalde, amir, ocre, prieto, rosete de } \\
\text { Brasil, azul fino. } \\
\text { Se utilizan finalmente albayalde y bermellón. }\end{array}$ \\
\hline & & $\begin{array}{l}\text { Temple 1. Sarga según las Ordenanzas de Córdoba de } 1493 \\
\text { a) anverso } \\
\text { b) reverso }\end{array}$ \\
\hline $\begin{array}{l}\text { Temple } 2 \\
\text { Sarga. Francisco Pa- } \\
\text { checo. } 1649\end{array}$ & $\begin{array}{l}\text { Cola } \\
\text { Yeso } \\
\text { Azarcón }\end{array}$ & $\begin{array}{l}\text { Capa de cola como preparación }(10 \mathrm{ml}) \text {. El texto no lo indica, pero se } \\
\text { realiza el dibujo con carbón y se repasa con negro carbón mezclado con } \\
\text { cola animal. } \\
\text { Como pigmentos se utilizan yeso y azarcón aglutinados con cola animal. }\end{array}$ \\
\hline & & $\begin{array}{l}\text { Temple 2. Sarga según Francisco Pacheco } \\
\text { a) anverso } \\
\text { b) reverso }\end{array}$ \\
\hline
\end{tabular}




\begin{tabular}{|c|c|c|}
\hline TEMPLE & MATERIALES & METODOLOGÍA APLICADA \\
\hline $\begin{array}{l}\text { Temple } 3 \\
\text { Sarga. Ordenanzas de } \\
\text { Madrid de } 1543\end{array}$ & $\begin{array}{l}\text { Sin preparación } \\
\text { Yeso } \\
\text { Azarcón }\end{array}$ & $\begin{array}{l}\text { Se siguen el resto de las indicaciones de Francisco Pacheco, próximas } \\
\text { en el tiempo. Se emplean, por tanto, la metodología y materiales del tem- } \\
\text { ple } 2 \text {, pero no se aplica preparación. }\end{array}$ \\
\hline & & $\begin{array}{l}\text { Temple 3. Sarga sin preparación (Ordenanzas de Madrid de 1543) } \\
\text { a) anverso } \\
\text { b) reverso }\end{array}$ \\
\hline $\begin{array}{l}\text { Temple } 4 \\
\text { Pintura aguazo. Desde } \\
\text { el s. XVI y citada } \\
\text { también en el XVIII. Se } \\
\text { unen en la probeta las } \\
\text { recomendaciones de } \\
\text { A. Palomino y las de F. } \\
\text { Pacheco } \\
\text { Pacheco: en su época } \\
\text { parece que se pinta- } \\
\text { ban en Italia y Flandes }\end{array}$ & $\begin{array}{l}\text { Cola animal } \\
\text { Carbón } \\
\text { Carmín } \\
\text { Azarcón } \\
\text { Yeso }\end{array}$ & $\begin{array}{l}\text { Según los textos, Pacheco: pintura aguazo: como aglutinante se utilizaba } \\
\text { cola y los pigmentos eran molidos al agua. Se humedece el lienzo por } \\
\text { detrás, bañando con agua la parte que se quiere acabar (sobre todo se } \\
\text { utilizaba para pinturas en blanco y negro o de color de bronce). Pigmen- } \\
\text { tos: verde montaña, verde terra y granillo además de los que ha citado } \\
\text { cuando se refiere al primer modo de temple donde incluye las sargas: } \\
\text { Yeso muerto, negro de carbón, jalde, añil, orchilla, cenizas, bermellón, } \\
\text { carmín, azarcón, Brasil, albayalde. } \\
\text { Según Palomino, el aguazo se realizaba sobre lienzo blanco y fino y no } \\
\text { se empleaba pigmento blanco. Se dibuja con un carbón, y se repasaban } \\
\text { los perfiles y se pasaba una aguada de carmín, con aguacola. Después } \\
\text { se humedece el reverso. } \\
\text { Teniendo en cuenta las recomendaciones anteriores, se realiza el dibujo } \\
\text { con carboncillo y repasa con carmín aglutinado con cola. Una vez seco, } \\
\text { se humedece el lienzo por detrás con un pulverizador y se pinta utilizan- } \\
\text { do yeso como blanco y azarcón. }\end{array}$ \\
\hline & & $\begin{array}{l}\text { Temple } 4 \text {. Pintura aguazo } \\
\text { a) anverso } \\
\text { b) reverso }\end{array}$ \\
\hline $\begin{array}{l}\text { Temple } 5 \\
\text { Temple parecido al } \\
\text { óleo, de F. Pacheco } \\
\text { s. XVII }\end{array}$ & $\begin{array}{l}\text { Cola animal } \\
\text { Pómez } \\
\text { Carbones } \\
\text { Negro carbón } \\
\text { Carmín } \\
\text { Huevo } \\
\text { Leche de higuera } \\
\text { Bermellón }\end{array}$ & $\begin{array}{l}\text { Se dan dos manos de cola ( } 10 \mathrm{ml} \text { cada una) y se suaviza con pómez. } \\
\text { Después se dibuja con carbón y se repasan los perfiles con negro car- } \\
\text { bón y carmín (Pacheco no lo indica pero los mezclamos con cola ani- } \\
\text { mal). Como aglutinante huevo entero con una hoja de higuera y diluido } \\
\text { todo ello en agua y batido hasta lograr espuma. Pacheco indica que } \\
\text { pueden utilizarse todos los pigmentos, pero hablando de encarnaciones } \\
\text { se refiere al bermellón, carmín, almagra y ocre. También puede utilizarse } \\
\text { negro de carbón y sombra de Italia. No hace referencia al blanco, pero } \\
\text { seguramente lo incluye al hacer referencia al posible empleo de todos } \\
\text { los pigmentos. } \\
\text { Se utiliza bermellón y blanco como pigmentos. }\end{array}$ \\
\hline & & $\begin{array}{l}\text { Temple 5. Referido por Francisco Pacheco como similar al óleo } \\
\text { a) anverso } \\
\text { b) reverso }\end{array}$ \\
\hline
\end{tabular}




\begin{tabular}{|c|c|c|}
\hline $\begin{array}{l}\text { Temple } 6 \\
\text { Pintura aguazo. Se } \\
\text { tienen en cuenta } \\
\text { fundamentalmente las } \\
\text { recomendaciones de } \\
\text { A. Palomino }\end{array}$ & $\begin{array}{l}\text { Cola animal } \\
\text { Carbón } \\
\text { Carmín } \\
\text { Azarcón }\end{array}$ & $\begin{array}{l}\text { Como blanco se emplea el del lienzo. Dibujo con carbón y repaso con } \\
\text { carmín y cola. Se pinta con azarcón. }\end{array}$ \\
\hline & & $\begin{array}{l}\text { Temple } 6 \text {. Aguazo sobre soporte blanco } \\
\text { a) anverso } \\
\text { b) reverso }\end{array}$ \\
\hline $\begin{array}{l}\text { Temple } 7 \\
\text { Aguadas de colores. } \\
\text { Citadas por Francis- } \\
\text { co Pacheco y otros } \\
\text { autores hasta el s. XX } \\
\text { Pintura a guazzo }\end{array}$ & $\begin{array}{l}\text { Alumbre } \\
\text { Tinta } \\
\text { Goma arábiga } \\
\text { Carmín }\end{array}$ & $\begin{array}{l}\text { Se ha utilizado un raso blanco. Se cuece agua con alumbre }(100 \mathrm{ml} \text { de } \\
\text { agua y } 5 \mathrm{~g} \text { de alumbre) y se ha aplica sobre el lienzo. Una vez seco, se } \\
\text { perfila lo dibujado (se ha dibujado con carboncillo) con tinta (se emplea } \\
\text { tinta china) y se aglutinan los pigmentos con goma arábiga diluida en } \\
\text { agua (proporción } 1: 2) \text {. El texto recomienda colores sin cuerpo como: } \\
\text { azafrán carmín, ancorca, etc. y de estos se elige el carmín para realizar } \\
\text { esta prueba. }\end{array}$ \\
\hline & & $\begin{array}{l}\text { Temple } 7 \text {. Aguadas de colores (sobre raso blanco) } \\
\text { a) anverso } \\
\text { b) reverso }\end{array}$ \\
\hline
\end{tabular}

\section{RESULTADOS Y CONCLUSIONES}

De los resultados obtenidos pueden extraerse ciertas conclusiones:

Primeramente, puede indicarse que los temples donde se ha aplicado preparación, es decir, los números 1, 2, y 5, presentan una impregnación del soporte mucho menor que la que puede observarse en los demás. Esta circunstancia se debe a que la preparación impregna las fibras textiles de manera que las capas superpuestas de pintura no pueden difundirse a través de ellas.

Si se observa el reverso de las probetas puede concluirse que la impregnación mayor se produce en el aguazo, tanto en el aplicado sobre el lienzo pardo como sobre blanco (temples 4 y 6). Por otra parte, también en la sarga en la que no se ha aplicado preparación, es decir, el temple 3, se observa una importante impregnación del soporte, si bien no es tan intensa como en el caso del aguazo. En este último caso, el de la pintura aguazo, la impregnación se debe a que durante su ejecución el soporte se mantiene húmedo, de manera que, cuando se aplica la pintura, el agua actúa como vehículo que la transporta entre las fibras textiles. En las aguadas de colores se aprecia 
igualmente una importante impregnación del soporte, tal y como muestran las imágenes aportadas.

Por otra parte, se observa una pincelada especialmente marcada en el primer temple, es decir, en la pintura de sargas sobre preparación de cola con miel y de yeso y cola. Los temples en los que se aprecia la pincelada en menor medida son el referido por Francisco Pacheco como similar al óleo, donde las dos capas de cola y su posterior pulimento con piedra pómez han suavizado la superficie y donde el huevo con su hoja de higuera y agua dan lugar a un aglutinante que permite transiciones suaves de pintura. Delicadas transiciones de color se aprecian igualmente en la muestra en la que se ha aplicado la técnica de la pintura aguazo.

Para finalizar, puede indicarse que la información aportada a lo largo del presente artículo así como las imágenes correspondientes a los diversos modos de temple pueden constituir una ayuda para el profesional a la hora de identificarlos y aplicarles su correcta denominación. 


\section{BIBLIOGRAFÍA}

- AGULló Y COBOS, M. (1978) Noticias sobre pintores madrileños de los siglos XVI y XVII. Granada: Departamento de Historia del Arte de las U. de Granada y Autónoma de Madrid, 1978

- BORREgo díAZ, P. J.; A. BUCES AGUAdO, J. A.; CARRASCO DAMIÁN, S. (2001) Proceso de conservación del aguazo "Oración en el Huerto" perteneciente a la Dirección General de Bellas Artes y Bienes Culturales del Ministerio de Educación, Cultura y Deporte. Pátina, vol. 10 y 11, 2001, pp. 4-11

- BRUQuetAS GALÁN, R. (2002) Técnicas y Materiales de la Pintura en los Siglos de Oro. Madrid: Caylus, 2002

- BUCES AGUADO, J. A. (2001) La sarga y el aguazo: dos técnicas pictóricas a examen. Pátina, vol. 10 y 11, 2001, pp. 58-70

- CALVO, A.; ROdRíGUEZ, L.; MANSO, B. (2002) Nuevas aportaciones a las técnicas de la pintura de sargas (la sarga de Santa Ana de la iglesia parroquial de Madarcos de la Sierra, Madrid). En Conservación del Patrimonio, evolución y nuevas perspectivas: Actas del I Congreso del GEIIC Valencia, España 25, 26 y 27 de noviembre de 2002. Valencia: Grupo Español del IIC, 2002, pp. 449-454

- CARDUCHO, V. (1981) Diálogos de la Pintura, Origen, Esencia, Definición, Modas y Diferencias (ed. prínc. de 1633, Madrid). En CALVO SERRALLER, F. La Teoría de la Pintura en el Siglo de Oro. Madrid: Cátedra, 1981

- CENNINI, C. (1988) El libro del arte (com. y an. por F. BRUNELLO). Madrid: Akal, 1988

- EAStaug, N. (2004) Pigment Compendium. A dictionary of Historical Pigments. Amsterdam: Elsevier Butterworth-Heinemann, 2004

- GRAMATKE, C. (2005) Aproximaciones a las fuentes del saber pictórico del siglo XVII. En Actas del II Congreso del GEIIC. Investigación en Conservación y Restauración. Universidad de Barcelona del 9 al 11 de noviembre de 2005, pp. 1-10

- ICRBC (1992) El retablo y la sarga de San Eutropio de El Espinar. Madrid: ICRBC, 1992

- MARTínEZ, F. (1989) Introduccion al conocimiento de las Bellas Artes o Diccionario manual de Pintura, Escultura, Arquitectura y Grabado (ed. facs. de la de Madrid, Viuda de Escribano, 1788). Málaga: Colegio Oficial de Aparejadores y Arquitectos Técnicos, 1989

- NUNeS, P. (1615) Arte Poética de Poesia et da Pintvra. Symmetria e Perspectiua. Lisboa: P. Crasbeeck, 1615
- ORDENANZAS de Sevilla de 1527. Recopilacion de las ordenanças de la muy noble e muy leal cibdad de Seuilla: detodas las leyes y ordenamientos antiguos y modernos: cartas y prouisiones reales: para la buena gouernacion del bien publico y pacifico regimiento de Seuilla y su tierra. Fecha por mandado delos muy altos y muy poderosos: catholicos reyes y señores don Fernando y doña Ysabel de gloriosa memoria y por su real prouision. Biblioteca Nacional, R3910, R Microfilm 11723, pp. CLXIIv-CLXIIIIr

- PACHECo, F. (1649) Arte de la pintura, su antiguedad y grandezas. Descriuense los hombres eminentes que ha auido en ella... y enseña el modo de pintar todas las pinturas sagradas. En Seuilla : por Simon Faxardo..., 1649

- PALOMINO DE CASTRO Y VELASCO, A. (1988) El museo pictórico y escala óptica (ed. prínc. de 1715-1724, Madrid). 3 Tomos. Madrid: Aguilar, 1988

- PILES, R. DE (1973) Les premiers éléments de la peinture pratique (ed. prínc. de 1684, París). Genève: Minkopf, 1973

- PINO, P. (1548) Dialogo di pittvra. Vinegia: per Pauolo Gherardo, 1548

- RAMíREZ DE ARELLANO, R. (1915) Ordenanzas de pintores. Academia. Boletín de la Real Academia de Bellas Artes de San Fernando, vol. 33, 1915, pp. 29-46

- RELLO, L. (2008) Términos de color en español: semántica, morfología y análisis lexicográfico. Definiciones y matices semánticos de sus afijos. Diálogo de la Lengua, vol. I, 2009, pp. 89-164

- RONCHETTI, G. (1912) Manual para los aficionados a la pintura (trad. de la 4. a edición italiana por María Ortíz y Ortíz). Madrid: [Eduardo Arias]: Romo, 1912

- SANTOS GÓMEZ, S.; SAN ANDRÉS MOYA, M. (2004) La pintura de sargas. Archivo Español de Arte. Tomo 77, n. ${ }^{\circ} 305,2004$, pp. 59-74

- SANZ, M. M. (1978) Un tratado de pintura anónimo y manuscrito del siglo XVII. Revista de ideas estéticas, 143, tomo XXXVI, 1978, pp. 252-275

- SOLER OLIVERES, J. (1998) Curso completo teórico práctico de diseño y pintura en sus tres principales ramos de olio, temple, y fresco (ed. facs. de la de Barcelona. Imprenta de José Torner, marzo de 1837). Valencia: Librerias "París-Valencia", [1998]

- VASARI, G. (1986) Le vite de' piú eccellenti architetti, pittori, et scultori italiani, da Cimabue, insino a' tempii nostri (ed. prínc. Florencia, 1550, pres. ed. mod. de Giovanni Previtali), 2 v. Turín: Einaudi, 1986 